\title{
RESEARCH INTO SPECIAL TECHNOLOGICAL EFFECTS FOR FORMATION OF WEAR RESISTANT COATINGS USING MINERAL RAW MATERIALS OF THE FAR EASTERN REGION
}

\author{
Viktor Makienko ${ }^{1 *}$, Igor Romanov ${ }^{1}$, Pavel Sokolov ${ }^{1}$, Alexander Atenyaev ${ }^{1}$ and Dmitry \\ Pervakov ${ }^{1}$ \\ ${ }^{1}$ Federal State Budgetary Educational Institution for Higher Education "Far Eastern State Transport \\ University"
}

\begin{abstract}
The results of the study of the possibility of using additional technological influence in the formation of doped coatings are presented. The distribution of thermal fields has been calculated, which makes it possible to estimate and predict the influence of additional influence on the formation of the coating in a simplified manner. Experimental studies have shown that additional technological influence promotes mixing of the melt, leading to an increase in the transition of alloying elements, as well as an increase in the mechanical properties and quality of the weld metal.
\end{abstract}

\section{Introduction}

Development and deployment of new materials for coatings and development of the methods for their quality control is an important line of research of materials science. Ferroalloys and pure-metal powders currently used for production of welding-surfacing materials significantly increase the cost of the materials produced. Therefore deployment of mineral raw materials without their deep technological processing when producing materials remains an issue of current importance. Production of welding-surfacing materials from mineral raw materials face problems caused by heterogeneity of the phase and chemical composition of the source mineral materials which in its turn causes irregular distribution of alloying elements in the coatings produced, low efficiency of alloying and, as a consequence - poor service properties $[1,2]$.

A promising direction of research focused on the improvement of the quality of coatings is the use of special technological methods for affecting the melt that involve simultaneous use of several concentrated sources of energy. In this work we suggest employment of one of the simplest and the most efficient methods of affecting the melt - a special arc of indirect action (SAIA) that serves as an additional source of thermal and electro-magnetic effect. This special arc facilitates redistribution of the temperature gradient and intensifies the molten pool agitation due to the interaction between the magnetic fields of the primary

\footnotetext{
* Corresponding author: mvm_tm@festu.khv.ru
} 
and indirect arcs which causes the deflection of the primary arc anode spot (of direct action) [3-6].

\section{Methodology of experiments}

Experimental research was conducted according to the flow-chart below (Fig. 1.) that reflects the sequence of work stages and theoretical prerequisites for use of the special arc of indirect action, as a source of additional impact on molten-pool while forming doped layer. The scheme below presents the major stages of the research from the setting forth of the hypothesis and development of a new technology for special affecting to the deployment of the technology developed to flux cored wires produced using mineral raw materials of the Far Eastern Region.

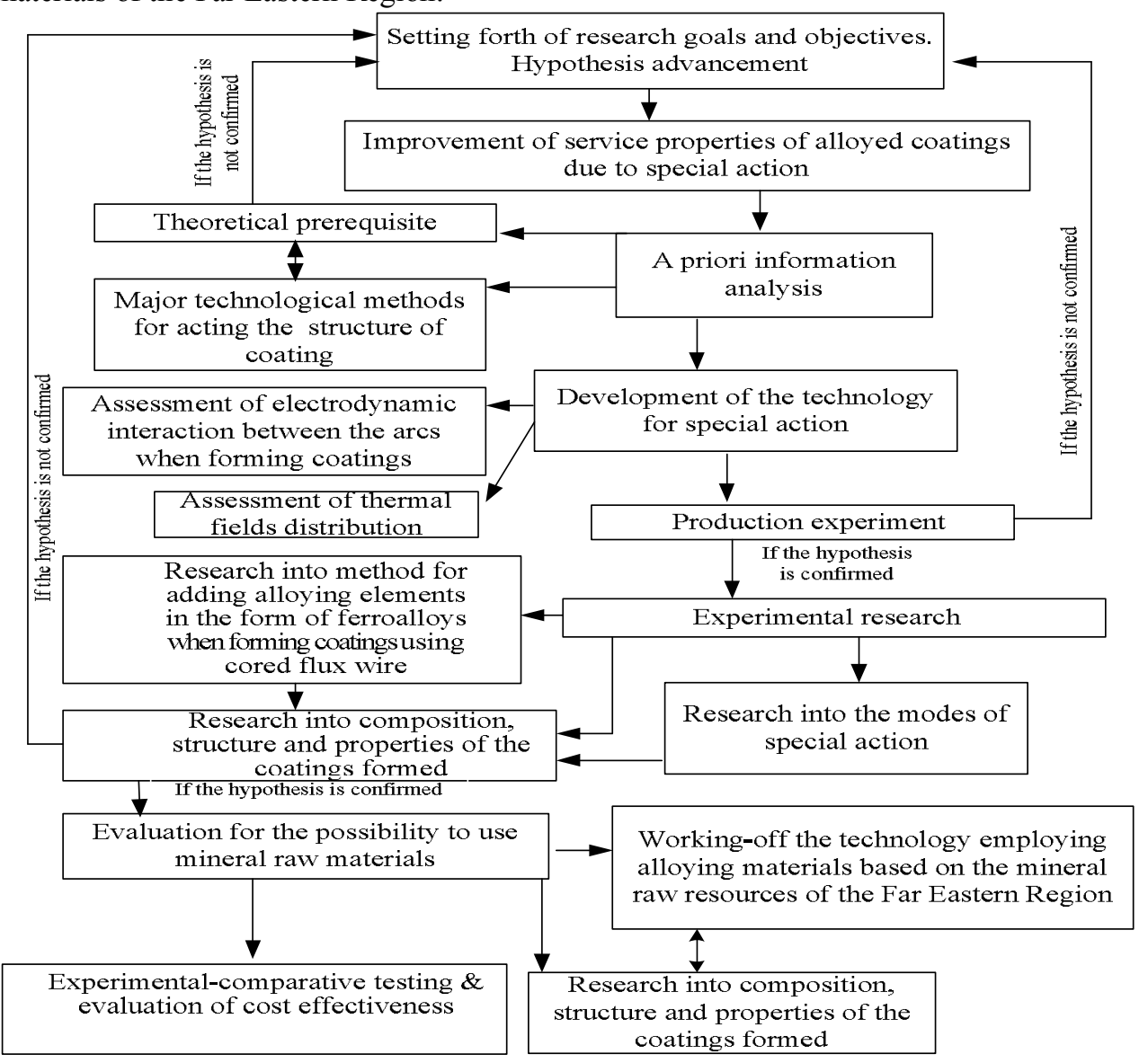

Fig.1. Flow-chart of research into the assessment of the special technological action on the coating formed

While conducting the research we performed theoretical calculation of the thermal fields and the electrodynamics interaction forces involved in the arc processes which allows us to determine the temperature distribution curves and to assess the efficiency of agitation and acceleration of the metallurgical processes under the impact of the special arc of indirect action [7-12].

In addition we used the experimental design methodology based on the experimental statistics methods aimed at determining the dependencies of influence of the special action parameters on the composition of the coatings being formed as well as determining optimal 
intervals for the variation of the SAIA modes for the maximum efficient alloying of the weld-metal. While planning the experiment we determined input $\left(\mathrm{X}_{1}, \mathrm{X}_{2}, \mathrm{X}_{\mathrm{i}}\right)$ and output (Y1, Y2, Yi) parameters subject to optimization (Fig. 2). Based on the calculated values we obtained mathematical dependencies that we used to diagram the influence of the special action modes on the composition of the coatings formed.

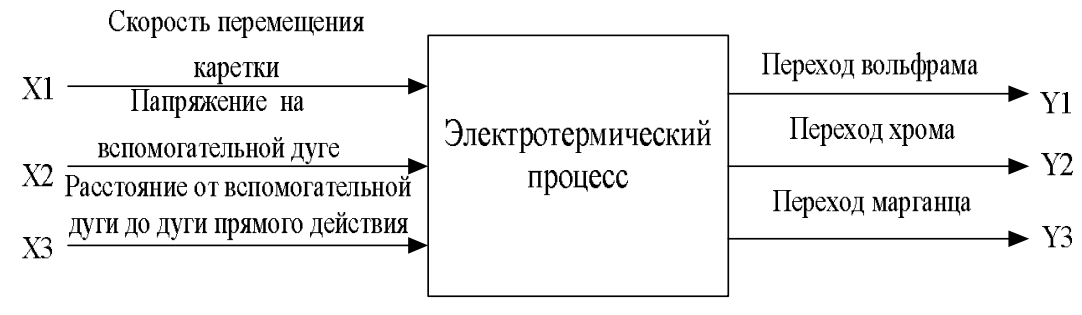

Входные параметры

Выходныс параметры

Fig. 2. Calculation model of the research into the influence of the input parameters on the composition of the coating formed.

\begin{tabular}{|c|c|c|}
\hline Frame travel rate & \multirow{3}{*}{ Electro-thermal process } & tungsten transition \\
$\begin{array}{c}\text { Special arc voltage } \\
\begin{array}{c}\text { Distance between primary and } \\
\text { special arc }\end{array}\end{array}$ & chrome transition \\
\hline Input parameters & & \\
& & Output paramese transition \\
\hline
\end{tabular}

\section{Results and discussions}

Calculation of the distribution of the thermal fields resulted in the temperature gradient distribution diagram presented in Fig. 3.

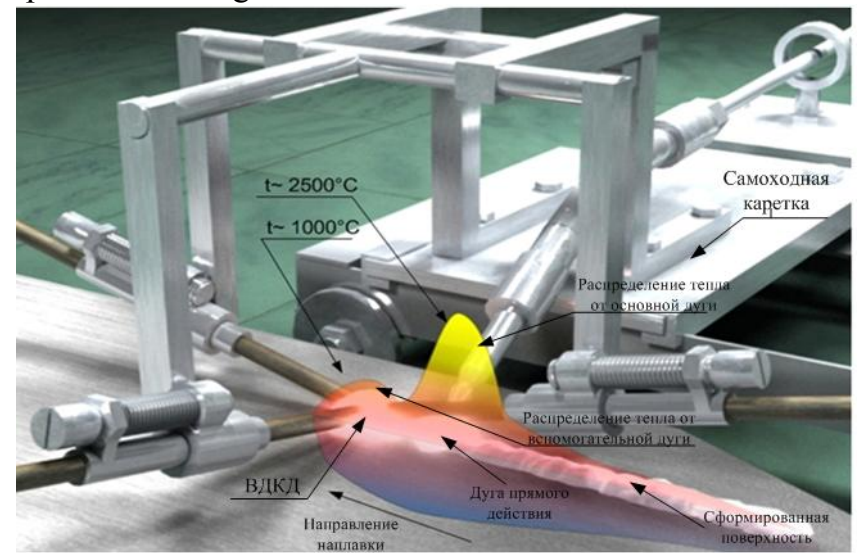

Fig. 3. Diagram of the temperature gradient distribution for primary and special arcs

Calculation of the thermal fields distribution showed that the action of the special arc on the surface being formed facilitates metallurgical processes, improves homogeneity of the structure and increases the transition of the alloying elements to the weld metal. These effects are caused by the redistribution of the heat flows as the heating-up temperature of the surface being formed by the special arc reaches $1000{ }^{\circ} \mathrm{C}$, and the temperature of the primary welding process is $3000{ }^{\circ} \mathrm{C}$. Calculation of the electrodynamic interaction force (EDI) between the primary and the special arcs testifies to the possibility to change the spatial position of the primary arc which causes mechanical agitation of the molten metal; if the distance between the arc centers is 4-6 mm, EDI force is $0.10-0.15^{*} 10^{-2} \mathrm{H}$. 
According to the methodology of the experimental research the next stage involved experiments aimed at determining the correlation between the input and output parameters of the electric arc process when the coating is formed using flux core wire effected by SAIA. The data obtained were used to plot the match diagram that defines the rational parameters for special action (Fig. 4).

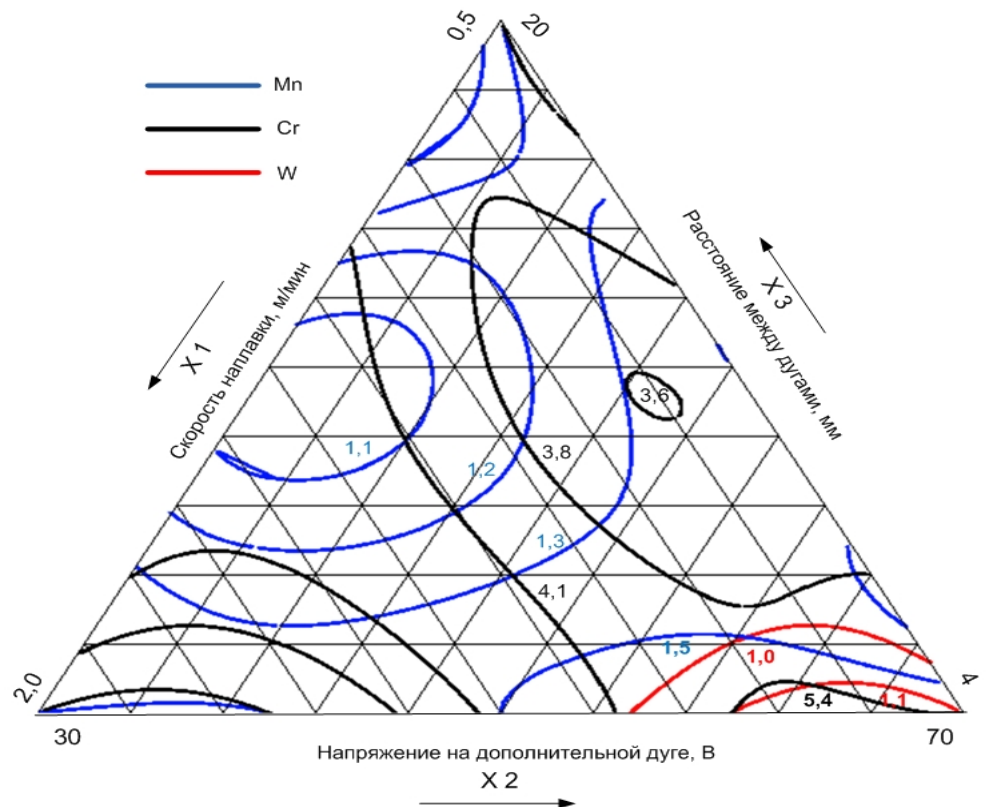

Fig. 4. Match diagram of the influence of the special action parameters on the composition of the coating

Analysis of the diagram shows that the rational modes of special action (the maximum efficiency of the alloying process and the content of the carbide constituent) are observed at the following values of the factors under research: distance between arcs is 4-6 mm; coating overlay rate is up to $0.6 \mathrm{~m} / \mathrm{min}$; SAIA voltage is $50-70 \mathrm{~V}$

During the next stage we investigated the structure, the composition and the properties of the coatings formed using SAIA (within the rational range of the modes) and without special arch action; their chemical compositions are presented in Table 1.

Table 1. Chemical compositions of the coatings formed

\begin{tabular}{|c|c|c|c|c|c|c|c|c|c|c|}
\hline Chemical element, $\%$ & $\mathrm{P}$ & $\mathrm{Si}$ & $\mathrm{Mn}$ & Mo & $\mathrm{S}$ & $\mathrm{Cr}$ & $\mathrm{W}$ & $\mathrm{Ti}$ & $\mathrm{Zr}$ & $\mathrm{C}$ \\
\hline Without special arc action & 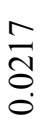 & $\begin{array}{r}\hat{0} \\
\text { o. } \\
0\end{array}$ & $\underset{\stackrel{m}{f}}{\stackrel{m}{f}}$ & 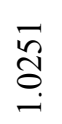 & $\begin{array}{l}0 \\
\stackrel{0}{0} \\
0 \\
0\end{array}$ & 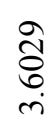 & $\frac{o}{\dot{+}}$ & $\begin{array}{l}\stackrel{8}{0} \\
\stackrel{n}{7} \\
\stackrel{0}{0}\end{array}$ & $\begin{array}{l}\hat{8} \\
8 \\
0\end{array}$ & $\begin{array}{l}\infty \\
\stackrel{1}{0}\end{array}$ \\
\hline Employing SAIA & $\begin{array}{l}\stackrel{\partial}{\sigma} \\
\stackrel{0}{0}\end{array}$ & $\begin{array}{l}0 \\
\text { లn } \\
\infty \\
0 \\
0\end{array}$ & $\stackrel{n}{\stackrel{n}{g}}$ & 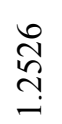 & $\begin{array}{l}\stackrel{+}{m} \\
0 \\
0\end{array}$ & $\begin{array}{l}\tilde{n} \\
\infty \\
n \\
n \\
n\end{array}$ & $\stackrel{\infty}{\infty}$ & 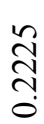 & $\begin{array}{l}\text { Jे } \\
8 \\
0 \\
0\end{array}$ & $\stackrel{n}{n}$ \\
\hline
\end{tabular}

Comparative analysis of the data in the Table 1 shows increased transition of the alloying elements to the metal formed using special arc. The distribution of the alloying elements in the coating has been examined in different points of the structural constituents and is presented in Fig. 5 (points 1-9) and Tables 2, 3. 


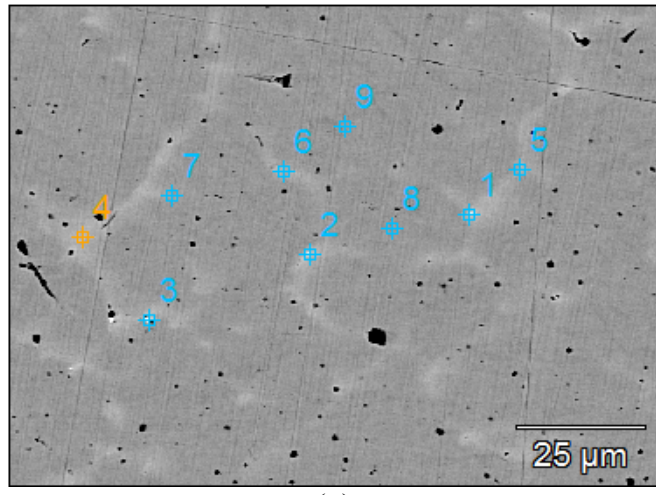

(a)

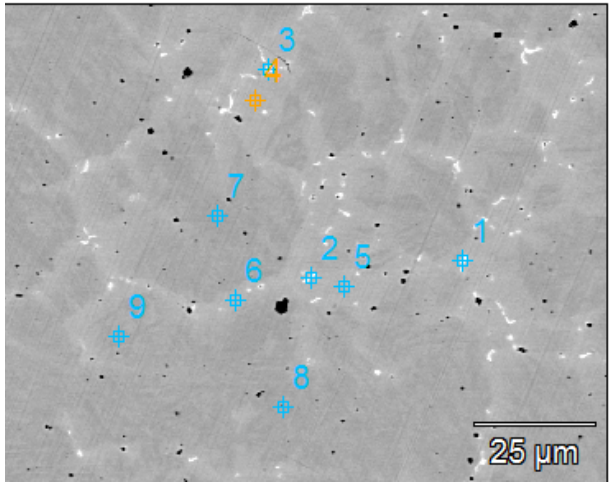

(b)

Fig. 5. Distribution of the elements on the surface of the coating formed:

(a) - without special arc action; (b) - employing SAIA

The distribution of the alloying elements on the surface of the coating was studied by reflected electrons and the data obtained show increased content of alloying elements $(\mathrm{Cr}$, $\mathrm{W}$, and $\mathrm{Mn}$ ) in the structural constituents of the samples formed using the special arc (Fig. $4 \mathrm{a}, \mathrm{b}$ and Tables 2,3 points 1-3).

Table 2. Distribution of the elements on the surface of the coating formed without special arc action

\begin{tabular}{|l|c|c|c|c|c|c|c|c|}
\hline \multirow{2}{*}{ Point } & \multicolumn{9}{|c|}{ Element, aтом. \% } \\
\cline { 2 - 9 } & $\mathrm{C}$ & $\mathrm{Si}$ & $\mathrm{Ti}$ & $\mathrm{Cr}$ & $\mathrm{Mn}$ & $\mathrm{Fe}$ & Mo & W \\
\hline 1 & 10.72 & & & 12.41 & 1.81 & 59.40 & 12.27 & 2.86 \\
\hline 2 & 9.07 & & 0.46 & 11.45 & 2.04 & 64.61 & 9.65 & 2.33 \\
\hline 3 & 19.95 & & 7.42 & 7.15 & 1.48 & 56.02 & 6.13 & 1.85 \\
\hline 4 & 3.45 & 1.73 & & 6.20 & 2.26 & 83.68 & 2.02 & 0.66 \\
\hline 5 & 3.61 & 1.56 & & 5.54 & 2.04 & 85.62 & 1.23 & 0.40 \\
\hline 6 & 3.87 & 1.53 & & 5.74 & 2.13 & 84.78 & 1.44 & 0.50 \\
\hline 7 & 3.10 & 2.41 & & 4.80 & 2.15 & 86.79 & 0.75 & \\
\hline 8 & 4.25 & 1.87 & & 3.66 & 1.48 & 88.34 & 0.41 & \\
\hline 9 & 4.10 & 1.99 & & 3.68 & 1.26 & 88.54 & 0.43 & \\
\hline
\end{tabular}

Table 3. Distribution of the elements on the surface of the coating formed employing SAIA

\begin{tabular}{|c|c|c|c|c|c|c|c|c|c|}
\hline \multirow{2}{*}{ Point } & \multicolumn{9}{|c|}{ Element aтом. \% } \\
\cline { 2 - 10 } & $\mathrm{C}$ & $\mathrm{Si}$ & $\mathrm{Ti}$ & $\mathrm{V}$ & $\mathrm{Cr}$ & $\mathrm{Mn}$ & $\mathrm{Fe}$ & Mo & $\mathrm{W}$ \\
\hline 1 & 22.19 & & & 0.38 & 13.46 & 2.23 & 46.67 & 12.68 & 2.40 \\
\hline 2 & 24.58 & & 0.20 & 0.47 & 13.51 & 1.95 & 44.79 & 11.53 & 2.98 \\
\hline 3 & 13.09 & & 16.09 & 0.62 & 6.22 & 1.70 & 51.02 & 7.57 & 3.69 \\
\hline 4 & 3.55 & 2.00 & & & 5.89 & 2.82 & 84.12 & 1.09 & 0.54 \\
\hline 5 & 12.00 & 2.08 & 0.19 & & 5.66 & 2.43 & 75.94 & 1.27 & 0.44 \\
\hline 6 & 3.72 & 2.03 & & & 6.55 & 2.86 & 82.49 & 1.69 & 0.66 \\
\hline 7 & 2.54 & 1.72 & & & 3.99 & 2.03 & 88.81 & 0.46 & 0.45 \\
\hline 8 & 2.38 & 1.71 & & & 3.92 & 1.90 & 89.33 & 0.47 & 0.30 \\
\hline 9 & 3.00 & 1.50 & & & 3.96 & 1.90 & 88.99 & 0.41 & 0.23 \\
\hline
\end{tabular}

Analysis of Fig. $4(\mathrm{a}, \mathrm{b})$ also shows growth of the area occupied by the alloying elements of structural constituent (light area points 1-6) with the overall composition of the coating (points 7-9) practically unchanged.

Microstructure of the coating formed without special arc action corresponds to the needled martensite containing retained austenite. In addition, the structure shows presence 
of carbide phase (1) Fig. 5 (a), hypothetically a complicated carbide of a cementite type which is confirmed by presence of a significant amount $(<5 \%)$ of alloying components in the coating formed. Microstructure of the coating formed employing SAIA is presented in Fig. 5 (b) and it differs from the structure formed by a conventional method (without SAIA). The major difference is the absence of distinct needled martensite structure and increase in the carbide constituent content (1). It should also be noted that the metal of the seam formed by SAIA is of troostite structure and the carbide constituent (light area) of a cementite type (hypothetically $[\mathrm{Fe} \mathrm{Cr} \mathrm{Mo} \mathrm{W}]_{3} \mathrm{C}$ ) is determined by the cut-\&-try method applied to the phases and their combining maximally approaching the stoichiometric composition.

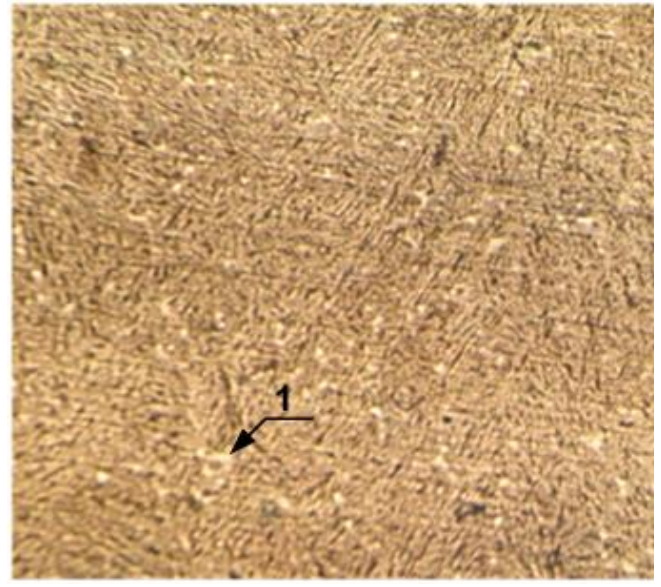

(a)

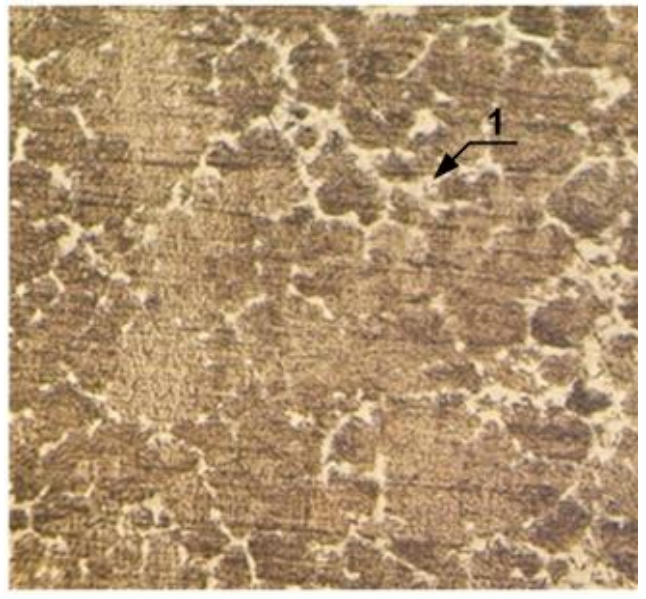

(b)

Fig. 6. Microstructure of the coating formed (x400): (a) - without special arc action; (b) employing SAIA

Microhardness of the coating formed without special arc action is 456-573 HV. .Microhardness of the coating formed under the SAIA action is 627-742 HV, which is 170 HV higher if compared with the metal formed without special arc action.

The final stage of our research included experimental-comparative testing of the parts of the road-construction machines restored using flux cored wire and SAIA technology. The testing conducted showed that wearability of these parts exceeds this property of the parts restored without using special technological effects of SAIA by $30 \%$.

\section{Conclusions}

1. We have scientifically substantiated the possibility for application of special technological effects when forming alloyed coatings and suggested the outline of research aimed at the assessment of the influence of a special technological action by SAIA on the layer formed by the flux cored wire containing alloying elements in the form of ferroalloys and mineral raw materials.

2. We have presented the methodology for experiment planning, theoretical calculation of thermal fields and electro-dynamic interaction of the arcs that allow of the evaluation and prediction of the special arc's influence on the coating formation. Based on the theoretical calculations we have developed experimental equipment for automated deposit welding process. 
3. Calculated distribution of thermal fields showed that effect of the special arc on the surface formed facilitates metallurgical processes, results in a more uniform structure and increases the transition of alloying elements to build-up metal. This effect is achieved due to redistribution of heat flows as the heating-up temperature of the surface being formed by the special arc reaches $1000{ }^{\circ} \mathrm{C}$, and the temperature of the primary welding process is 3000 ${ }^{0} \mathrm{C}$. Calculation of the electrodynamic interaction (EDI) force between the primary and the special arcs testifies to the possibility to change the spatial position of the primary arc which causes mechanical agitation of the molten metal.

\section{References}

1. Verhoturov A. D., Babenko E. G., Makienko V. M. Metodologiya sozdaniya svarochnyh materialov [Methodology for production of weld materials] / Edited by Corresponding Member of the Russian Academy of Science Voronov B.A. - Khabarovsk, FESTU Publ. 128 p. (2009)

2. Lashchenko G.I. Kombinirovannye tehnologii svarki plavleniem [Combined technologies for fusion welding] // Avtomaticheskaya svarka [Automated welding]. 8. (2012)

3. Saraev Y.N., Lebedev V.A., Novikov S.V. Mashinostroenie [Engineering Industry]. 4 (1). pp. 16-2634. (2016)

4. Matsunawa A., Mizutani M., Katayama S., Seto N. Po-rosity formation mechanism and its prevention in laser welding, Welding International. 17(6). 431-437. (2003)

5. Rykalin N.N. Raschety teplovyh poley pri svarke [Calculation of thermal fields under welding], Moscow, Mashgiz Publ. 296 p. (1951)

6. Y.G. Gagen, V.D. Taran Svarka magnitoupravlyaemoi dugoi [Magnetically operated arc welding]. Moscow, Mashinostroenie Publ. 160 p. (1970)

7. Goldak J., Chakravarti A., Bibby M. A new finite element model for welding heat source//Metallurgical Transactions B. 15B. P. 299-305. (1984)

8. Nguyen. N.T., Mai Y.-W., Simpson S. and Ohta A.. Analytical approximate solution for double ellipsoidal heat source in finite thick plate//Welding Journal. 3. P.82-s93-s. (2004)

9. Sabapathy P.N., Wahab M.A., Painter M.J.: Numerical methods to predict failure during the in-service welding of gas pipelines//Journal of Strain Analysis. 36 (6). P. 611619. (2001)

10. Zhang J. and Dong Y. Method for determining a heat source model for a weld. US Patent No 6,324,491 B1. 2001.

11. Goldak J. [et al.] Computer Modeling of heat flow in welds// Metallurgical Transactions B. 17B. pp. 587-600. (1986)

12. Ranatowski E., Pocwiardowski A. An analytical-numerical evaluation of the thermal cycle in the HAZ during welding', Mathematical Modelling of Weld Phenomena 4, H. Cerjak (ed.), IOM Communications Ltd, London.pp. 379-395. (1998) 